\title{
Dynasties in professions: The role of rents
}

\author{
Sauro Mocetti *
}

\begin{abstract}
The correlation between the socio-economic status of parents and their offspring has emerged as one of the stylized facts in economics, though cross-country and cross-occupation variation is remarkable. However, part of the underlying mechanism behind intergenerational persistence remains to be explained. This paper contributes to the existing literature by providing evidence on the role of rents, i.e., (unfair) economic benefits that individuals obtain as adults because of their parents' professional position. Several identification strategies, including the exploitation of discontinuities in regulation, suggest that rents significantly affect children's propensity to follow their parents' professional career path. From a policy perspective, the removal of anti-competitive regulations and other positional advantages may increase both social fluidity and labor market efficiency.
\end{abstract}

Keywords: intergenerational mobility, professions, regulation, rents.

JEL codes: J62, J44.

\footnotetext{
* I thank Guglielmo Barone, Gaetano Basso, Vincenzo Mariani and seminar participants at the Bank of Italy for comments and suggestions that have helped improve the paper. The opinions expressed herein are my own and do not necessarily reflect those of the Bank of Italy. Email: sauro.mocetti@bancaditalia.it.
} 


\section{Introduction}

The positive correlation between the socio-economic status of parents and their offspring has emerged as one of the stylized facts in economics and sociology. Abundant empirical evidence - reviewed by, among others, Solon (2002), Björklund and Jäntti (2009), Black and Devereux (2011), and Corak (2013) - indicates a positive correlation between incomes across generations. Björklund et al. (2012) also find evidence of dynasties at the top of the income distribution in Sweden, a country known for its high degree of social fluidity. Similarly, several papers document the tendency of children to be employed in the same occupation as their parents - see Lentz and Laband (1989), Laband and Lentz (1992), Dunn and Holtz-Eakin (2000), and Corak and Piraino (2011). Beyond the existing literature, anecdotal stories about dynasties in professions are countless in every city.

Examining the mechanisms behind career following, a stream of literature has largely focused on nature versus nurture, i.e., the relative importance of an individual's innate qualities (nature) versus the role of personal experiences, such as family upbringing, peer groups, and other environmental factors (nurture). ${ }^{1}$ These factors might favor the transmission of occupation-specific human capital within the family and therefore the intergenerational persistence in professions (and incomes). However, career following is also partially linked to economic advantages transmitted in adulthood through, for example, family ties, social networks, and the other benefits of parents' positional advantage (Ioannides and Loury, 2004; Granovetter, 2005). The role of these connections can be compared to a two-sided coin. On the one side, the connections may improve welfare by conveying a wealth of reliable information, acting as a source of peer monitoring and emphasizing the role of trust. On the other side, however, the connections may hide nepotism and corporative practices, thus representing a source of both inefficiency and persistent inequality.

Understanding the underlying causes of intergenerational persistence is important to determine a socially optimal level of mobility and thus to design proper policies to attenuate the role of factors that are considered unfair. ${ }^{2}$ Unfortunately, as acknowledged by Smeeding et al. (2011), the existing literature on intergenerational mobility provides few clues about the role of the welfare state and labor market institutions. Equality of opportunity has primarily been pursued by democratizing access to education, and there is almost no research on other issues, such as market regulation. This focus of the literature is also due to the difficulty in empirically distinguishing a career following that is motivated by an intergenerational transfer of career-specific human capital and preferences (through

\footnotetext{
${ }^{1}$ See Bowles et al. (2005), Björklund et al. (2006) and Sacerdote (2011) for a discussion on the role of preand post-birth factors. Their evidence suggests that genetics and environmental factors contribute significantly to the transmission of income and also positively interact, i.e., genetically disadvantaged children benefit less from an improved environment than more able children do.

${ }^{2}$ For a discussion on the fairness of inequality and on the relationship between intergenerational mobility and equality of opportunity, see Roemer (2002 and 2004), Swift (2004), Jencks and Tach (2006), Ichino et al. (2011) and Corak (2013).
} 
either nature or nurture) from a career following that is caused by positional rents.

The aim of this paper is to show how institutions, particularly economic regulations, affect intergenerational mobility. Economic regulations that are restrictive and hostile to competition provide market power to incumbents, constitute barriers to entry, and ultimately generate rents (i.e., unfair economic benefits that individuals obtain because of their parents' professional position). Rents in turn represent the economic prerequisite for socially undesirable behaviors, such as nepotism, corporative practices, and other types of family favoritism.

To obtain clear evidence of the nexus between rents and social fluidity, we focus on the profession of pharmacists in Italy. Italy provides an interesting case for study because it is one of the most immobile societies (Corak, 2013) and one of the most regulated economies (OECD, 2011) among developed nations. Therefore, regulation and positional rents may help to explain the lower degree of social fluidity in this country. Moreover, the labor market for pharmacists presents peculiar features that are useful for our identification strategies. First, in Italy, inheriting the family pharmacy is one of the most common ways to become a pharmacist. Therefore, pharmacists' children benefit from a clear positional advantage compared to other children. Second, and more interestingly, the economic rent of a pharmacy (i.e., the market power proxied with the number of pharmacies per thousand residents) is highly heterogeneous across cities, reflecting a demographic criterion stated by Law 475/1968. ${ }^{3}$ Namely, the Law establishes a set of population thresholds at which the number of pharmacies that should operate in a city changes discontinuously.

The dataset consists of a sample of young people for whom we observe, among other variables, whether they are enrolled in a pharmacy program at a university (i.e., their propensity to become pharmacists) and whether they are children of a pharmacist. These data are matched with the number of existing pharmacies at the local level. We apply two empirical strategies to identify the causal effect of the economic rents of pharmacies on an individual's propensity to become a pharmacist. First, we restrict the analysis to pharmacists' children and use the economic rent function induced by the regulation to construct instrumental variable estimates of the (observed) economic rent. This strategy as performed by Angrist and Lavy (1999) with Maimonides' rule for class size - exploits the fact that the regressor of interest is partially determined by a known discontinuous (non-linear and non-monotonic) function of an observed covariate (population). Therefore, we can control for a wide range of smooth population effects when using the rule as an instrument. This approach can be viewed as an application of the regression-discontinuity design. Second, we consider the full sample of young people and run a regression in which the local pharmacies' economic rents are interacted with the parents' profession(s). This strategy allows for the inclusion of city-fixed effects, which control for all of the unobserved heterogeneity (at the local level) that may affect the children's propensity to become pharmacists. The estimate of the interaction term captures the differential effect of

\footnotetext{
${ }^{3}$ Calzolari et al. (2013) find that the variation in the number of pharmacies at the local level is associated with the degree of competition and the capacity of pharmacists to extract a surplus. Our paper complements their analysis by showing that rents affect not only prices but also the allocation across occupations.
} 
pharmacies' economic rents on pharmacists' children (who may inherit the business and benefit from a positional advantage) with respect to other children.

We document that the propensity for pharmacists' children to become pharmacists (15.9 percent) is remarkably higher than the propensity for the remainder of the population (1.3 percent). Notably, parental education and familiarity with the medical field explain only a minor portion of the difference (the corresponding figure is 4.5 percent among the children of doctors or somewhat-related professions). Conversely, our empirical findings suggest that positional rents (the inheritability of the business and the economic rents guaranteed by favorable pharmacy-to-population ratios) play a major role in this decision. Specifically, we find that adding a new pharmacy in each city would reduce the probability of pharmacists' children enrolling in a pharmacy degree program by nearly 4 percentage points, which corresponds to one fourth of the predicted probability. The impact is even stronger around the thresholds and in smaller cities, where the effect of the regulation is larger; the children's propensity to follow their parents' career decreases sharply from 18 to 6 percent from a city just below the first population threshold to a city just above it. Moreover, the impact of economic rents is sizeable and highly significant for the career choices of pharmacists' children and is negligible for other children, thus suggesting that entry barriers and the inheritance of the family business heavily affect the intergenerational persistence among pharmacists.

To the best of our knowledge, this paper is the first to focus on the role of regulation and rents in the literature on inequality and intergenerational mobility. Indeed, the overwhelming majority of existing empirical studies that examine the factors responsible for the observed intergenerational persistence are focused on nature versus nurture and on the mediating role of the education system (Black and Devereux, 2011). Surprisingly, the role of regulation, which may heavily affect economic returns and barriers to entry in certain professions, is largely neglected in the literature. ${ }^{4}$ A further novel element of this study is the empirical strategy, which allows for the identification of a causal nexus (from rents to career following), thus overcoming the descriptive approach prevailing in previous studies on occupation persistence. From a policy perspective, our findings indicate that the role of family background may be sizeable in adulthood and not only in upbringing. Therefore, any policy that removes guild privileges and generally reduces rent positions in the labor market may increase social fluidity and (plausibly) may lead to a more optimal allocation of resources across occupations. In this respect, our findings are consistent with those of Bandiera et al. (2009), who, using a controlled field experiment, find that managers favor the workers to whom they are socially connected when faced with lowpowered incentives.

The remainder of the paper is organized as follows. Section 2 briefly reviews the literature and provides background information on Italy and the pharmacist labor market. Sections 3 and 4 describe the data and empirical strategies, respectively. Section 5 reports the results, and Section 6 offers concluding remarks.

\footnotetext{
${ }^{4}$ See Kleiner and Krueger (2013) for an analysis of occupational licensing in the US.
} 


\section{Background discussion}

Intergenerational persistence in socio-economic status has been observed in all of the societies studied thus far, although there is considerable cross-country variation (Corak, 2013). Existing estimates of the extent to which sons' earnings correlate with those of their fathers (i.e., the "intergenerational earnings elasticity") are particularly pronounced in the United Kingdom and Italy, where approximately half of the economic advantage that highearning fathers have over low-earning fathers is transmitted to their sons (Figure 1). Conversely, persistence is comparatively low in the Scandinavian countries and Canada, with less than 20 percent of the wage advantage being passed on from fathers to sons.

Cross-country heterogeneity is typically attributed to differences in the institutions and in the effectiveness of policies that countries deploy in their efforts to equalize opportunities. The overwhelming majority of studies focus on the education system, from early childhood education and care to measures favoring access to tertiary education (OECD, 2010). However, a portion of cross-country heterogeneity remains unexplained.

Cross-profession variation in intergenerational persistence is also large, although substantially uninvestigated. Career following is particularly widespread among children of legislators and senior officials, children of members of the armed forces, and children of workers in the agricultural sector. Among the members of professions, the likelihood of being employed in the life sciences and health sectors for children of those who had a similar profession is nearly five times the corresponding figure for the overall population (Figure 2). ${ }^{5}$ Basso and Labartino (2011) provide descriptive evidence on family connections across professions in Italy using the distribution of surnames within a profession (relative to the distribution in the overall population) as an indicator. According to their results, family connections are strongest among doctors, pharmacists, and lawyers (Figure 3). ${ }^{6}$

The cross-occupation heterogeneity in intergenerational persistence and the higher relevance of dynasties in certain professions may be attributed to a number of reasons that are difficult to isolate from each other. ${ }^{7}$ First, parents may influence their children through the genetic transmission of characteristics, such as innate abilities and personality traits that are valued in the labor market. Second, parents may subtly influence the lifetime earnings prospects of their children through family culture and other monetary and nonmonetary investments that shape skills, aptitudes, beliefs, and behaviors. Third, parents may transmit economic advantages through social connections (e.g., facilitating access to

\footnotetext{
${ }^{5}$ These figures have been computed with data drawn from the EU-SILC. The wave conducted in 2005 contains a specific section concerning intergenerational mobility, in which numerous aspects of family background (including parents' occupations) are recorded in a retrospective fashion, i.e., by collecting information on family background for the period when the interviewee was approximately 14 years old.

${ }^{6}$ See Durante et al. (2011) for an analysis of familism and nepotism in Italian academia.

${ }^{7}$ Moreover, each of these channels is associated with a different (ethical) view about what is an indefensible or socially acceptable source of inequality. See Roemer (2002 and 2004) for a useful framework to distinguish between fair and unfair channels through which family background may affect children's outcomes.
} 
jobs and admission to college) and other positional advantages. The relevance of each channel may clearly vary to a large extent across professions.

Previous papers addressing career following shed some light on these channels and on their differential relevance across occupations. Lentz and Laband (1989) find that the children of doctors are more likely to be admitted into medical school than the general population (i.e., after having controlled for acquired human capital) and infer that the primary cause of this tendency is nepotism. Laband and Lentz (1992) suggest that career following among lawyers is linked primarily to the transfer of occupation-specific human capital. Dunn and Holtz-Eakin (2000) examine persistence in self-employment and document the strong role of within-family transmissions of non-monetary resources, such as work experience, managerial human capital, and industry-specific knowledge. Corak and Piraino (2011) find that a significant proportion of Canadian men have been employed at a point in time with an employer for which their father also worked and suggest a role of informational networks, parental influence on the hiring process, and firm-specific attributes passed from fathers to sons. Björklund et al. (2012) suggest that wealth is the most likely channel for the (remarkably) high correlation at the top of the income distribution in Sweden. However, these results, while suggestive, are largely descriptive and cannot be interpreted as causal evidence. For example, the role of nepotism can be confounded by the omission of variables that are difficult to observe, such as preferences, aspirations, skills, and genetics.

In this paper, we argue that rents play a critical role in explaining both cross-country and cross-occupation variation in intergenerational persistence. The descriptive evidence reported in Figure 4 supports this argument. Indeed, in countries considered friendly regarding the market mechanisms of regulatory environments, the probability of becoming a member of a profession if one's parent is a member of a profession is between twice and three times the corresponding probability of the remainder of the population. Conversely, in countries with a particularly restrictive regulatory environment, the probability of children following in their parents' footsteps is, relative to the general population, considerably (up to seven times) higher. An obvious interpretation of these findings is that economic regulations provide market power to incumbents, constitute barriers to entry, and ultimately generate rents. Thus, the children of members of a profession may benefit from their parents' positional rents and are more likely to follow in their parents' footsteps.

To find clean evidence of the nexus between rents and intergenerational mobility, we focus on the profession of pharmacists in Italy. As stated above, Italy is an interesting case for study because it is one of the most immobile societies and one of the most regulated economies among developed countries. ${ }^{8}$ Pharmacists, in turn, are among the top earners in Italy, below notaries (Figure 5), and their market regulation has some attractive features that are helpful with regard to our identification strategy.

To become a pharmacist, one must obtain a bachelor's degree in pharmacy or pharmaceutical chemistry and technology; the five-year degree program also includes a

\footnotetext{
${ }^{8}$ See Mocetti (2007) for a richer analysis on intergenerational mobility in Italy.
} 
six-month internship to be conducted at a pharmacy or in a hospital. Therefore, being enrolled in a pharmacy degree program clearly indicates the individual's propensity to become a pharmacist. After graduation, one must pass the state exam that enables entry into the order of pharmacists. ${ }^{9}$ Unlike other professional services, pharmacists are primarily engaged in retail trade. Thus, the ownership of a pharmacy is a key element of this profession. For a regularly registered pharmacist, there are only three ways to become an owner of a pharmacy: participating in a public competition based on qualifications for the allocation of new or vacant pharmacies; buying an existing license (which is a rare event); or inheriting an existing pharmacy from parents. Therefore, being the child of a pharmacist provides a strong positional advantage. Another key feature of this profession is that entry into the market is highly regulated. Law 475/1968 establishes the number of pharmacies that should operate in a city as a function of the existing population; for example, there should be only one pharmacy in a city with fewer than 7,500 residents; there should be two pharmacies in a city with 7,500 to 12,500 residents; and above this threshold, a new pharmacy should be added for every 4,000 residents. ${ }^{10}$ Therefore, economic rent (i.e., the number of pharmacies per thousand residents) changes discontinuously with population size. ${ }^{11}$

These features will be exploited in the empirical strategy, as discussed in Section 4.

\section{Data}

Data are drawn from the Labor Force Survey (LFS). Specifically, we work with a sample of young people aged 18-25 who are recorded as children in the survey and therefore can be easily matched to their parents. This choice provides us with detailed data covering two generations. ${ }^{12}$ To increase the size of the sample, we pool waves from 2005 to 2011. Focusing on co-residing parents and children has two primary drawbacks. First, although parents are observed in adulthood, young people have not yet entered the labor market. However, we do observe whether children are enrolled at a university and, if so,

\footnotetext{
${ }^{9}$ The degree of selectivity to achieve professional certification is arguably negligible. According to Catania and Monti (2011), the pass rate for pharmacists was 97 percent. Geographical differences in the pass rate were also small, ranging from 86 percent in Rome to 100 percent in eight provinces (either from the South or from the North).

${ }^{10}$ Their location is also highly regulated; in each municipality, the distance between two different pharmacies cannot be shorter than 200 meters.

${ }^{11}$ There have been two important reforms in the pharmacy market in the past decade. In 2007, the legal monopoly on over-the-counter (OTC) drugs was abolished (OTC drugs are medicines sold directly to a consumer without a prescription). In unreported evidence we have found that controlling for this nationwide reform does not affect our estimates. In 2012, a new law on pharmacies became effective, partially liberalizing the sector and lowering the thresholds in the relationship between the population and number of pharmacies. Our sample period is not affected by this change.

${ }^{12}$ It is difficult to identify intergenerational linkages for specific professions within a population because information on family relationships is generally unavailable or relatively scant and reported retrospectively (with errors). An appropriate dataset that spans at least two generations is the main problem in the empirical literature on intergenerational mobility.
} 
their degree programs. Therefore, we measure the individual propensity to become a pharmacist with a dummy that indicates whether children pursue a pharmacy course of study. Conversely, the parents' professions are correctly observed with the 3-digit ISCO occupational classification. Second, focusing on young people still living with their parents may lead to a sample selection bias. However, the fraction of young people living with their parents in that age bracket exceeds 90 percent; therefore, it is reasonable to argue that the role of selection (if any) is fairly limited. ${ }^{13}$

The main descriptive statistics are reported in Table 1. Of the approximately 330,000 children in the sample, nearly half are female. One third of the young people are enrolled at a university, with 1.3 percent pursuing a pharmacy degree. The heads of households (parents of the young people) are in their fifties, and the proportion of those with a university degree is slightly less than 13 percent, whereas the proportion of pharmacists in the sample is even lower (0.04 percent). ${ }^{14}$ As shown in Figure 6, the propensity to become a pharmacist among pharmacists' children (15.9 percent) is considerably higher than the mean (1.3 percent). This higher propensity to become a pharmacist is not attributed to the higher education of parents (3.0 percent among the children of those with a college degree) or to the children's familiarity with the medical field (4.5 percent among the children of doctors or somewhat-related professions).

Microdata from the LFS are matched with city-level data on the number of pharmacies drawn from the Ministry of Health and are enriched with other local variables, such as population, collected by Istat, the National Institute of Statistics.

Figure 7 illustrates how the observed number of pharmacies in each city varies with population size in our sample. The pattern approximately mirrors a "step" graph, although compliance with the predicted values (by the demographic criterion) is imperfect for two reasons. First, cities characterized by peculiar geographic features (e.g., mountainous and isolated cities) are allowed to have more pharmacies than what would be implied by the demographic criterion. Second, over the past several decades, pharmacies were opened when the population exceeded the threshold but were not necessarily closed when the population declined below the threshold.

Table 2 presents a more standard and robust analysis of the relationship between the two variables. Specifically, we report regressions at the city level with the observed pharmacy-to-population ratio as a dependent variable and the predicted ratio as an explanatory variable. Column 1 is without controls, whereas columns 2 to 5 add polynomial specifications of increasing order to the population. The coefficient of interest is relatively stable, positive (as expected), and highly significant in each specification.

\footnotetext{
${ }^{13}$ We do not know, by construction, the family background of the young people who do not co-reside with their parents. In the majority of cases, these young people are already active in the labor market; among women, there is a large fraction of housewives. Conversely, the fraction of students is considerably low (16 percent, or approximately one third of the corresponding figure for co-residing children). Regarding those who are enrolled in a pharmacy degree program, only 3 percent do not live with their family. Overall, these figures suggest that selection is not an issue in this case.

${ }^{14}$ Pharmacists are identified using the three-digit ISCO occupation classification.
} 


\section{Empirical strategy}

We pursue two empirical strategies to identify the causal effect of regulation on intergenerational persistence in the pharmacist profession.

\subsection{Regression-discontinuity design}

In the first empirical strategy, we restrict the analysis to the pharmacists' children. Put simply, we consider two children of two pharmacists and examine whether their propensity to become pharmacists themselves (after controlling for a rich set of observables) depends on the different economic rents of their parents' pharmacies (which in turn depends on the city in which they are located). Formally,

$$
\text { pharmacist }_{i}^{c}=\text { Brent }_{c(i)}+\delta X_{i}+\gamma Z_{c(i)}+\mu_{i}
$$

where the dependent variable is the propensity of child $i$ to become a pharmacist (proxied by enrollment in a pharmacy degree program), similar to his/her parents, and $\operatorname{rent}_{c(i)}$ is the pharmacy-to-population ratio in city $c$ where child $i$ resides; moreover, we include controls at the individual $(X)$ and city $(Z)$ level.

However, there are several potential biases from simple ordinary least squares (OLS) evidence, as shown in equation (1), with the most obvious being omitted variable biases. Indeed, non-compliance with the demographic criterion may be endogenous if the choice to close a pharmacy when the population declines below a certain threshold is correlated with the outcome variable. Moreover, there may be unobserved features of the cities that affect both the number of allowed pharmacies and the career choices of the young people. Finally, the pharmacy-to-population ratio varies with population size, which may be correlated with other unobserved variables that may influence the children's propensity to become pharmacists. For example, there may be more employment opportunities in larger cities, which may affect children's professional aspirations and choices. Moreover, enrollment costs may be greater for those living in smaller cities (i.e., those that are more distant and less connected to university cities).

To address these concerns, we analyze the fuzzy regression discontinuity induced by the demographic criterion in an instrumental variable framework, as conducted by Angrist and Lavy (2009) using Maimonides’ rule. Formally, we rewrite equation (1) as follows:

$$
\text { pharmacist }_{i}^{c}=\operatorname{\beta rent}_{c(i)}+g\left(\text { pop }_{c(i)}\right)+\delta X_{i}+\gamma Z_{c(i)}+\mu_{i}
$$

where $\operatorname{rent}_{c(i)}$ is instrumented by $\widehat{\operatorname{ent}}_{c(l)}$, which is the pharmacy-to-population ratio predicted by the demographic criterion; $g\left(p o p_{c(i)}\right)$ is a (various degree) polynomial function in the forcing variable (population).

The instrumental variable estimates of equation (2) use discontinuities in the relationship between population and economic rent (captured by $\widehat{r e n t_{c(l)}}$ ) to identify the causal effect of the latter while including a high order polynomial in the forcing variable, 
i.e., $g\left(p o p_{c(i)}\right)$, to control for a wide range of smooth population effects. The causal interpretation is based on the (reasonable) assumption that after having controlled for smooth population effects and all of the other covariates, the only reason for any association between the instrument and dependent variable is the association between the predicted and observed pharmacy-to-population ratio. We expect that $\beta$ enters with a negative sign, which indicates that an increase in the number of pharmacies relative to the population would reduce economic rents and thus the children's propensity to follow their parents' footsteps. Notice that an increase in the number of pharmacies above the threshold would also imply an increase in the labor demand, which would positively affect the propensity to enroll in a pharmacy degree program. Thus, our estimates should be interpreted as a lower bound of the effects of economic rents.

One threat to the validity of the regression-discontinuity design is bunching on one side of the thresholds, which would suggest that the forcing variable is manipulated. Figure 8a presents the population distribution of cities with less than 20,000 residents, where discontinuities induced by regulation are larger. Figure $8 \mathrm{~b}$ presents the distribution in the bandwidth $\pm 2,000$ from thresholds, pooling all cities. Visual inspection reveals no suspect discontinuities in the distribution of the forcing variable. More formally, the test developed by McCrary (2008) confirms that the hypothesis of non-random sorting around the thresholds is rejected. ${ }^{15}$ The manipulation of city size by pharmacists, which occurs if pharmacists self-select in certain cities with a more profitable pharmacy-to-population ratio, is limited by the fact that regulation heavily constrains strategic entry into the market. $^{16}$

The identification assumption in a regression-discontinuity framework is that cities just above the threshold are similar to those just below the threshold. This assumption would imply that differences in the outcomes are caused solely by differences in the treatment (Lee and Lemieux, 2010). To verify whether this assumption is accurate, we test the differences in the means for several characteristics around the thresholds. The results reported in Table 3 refer to different bandwidths $( \pm 2,000$ in columns I and II and $\pm 1,000$ in column III) and different samples of cities (in columns II and III, the analysis is restricted to cities with less than 20,000 residents). As expected, the difference in the number of pharmacies is both statistically and economically significant. Among local observables, we include the following: the unemployment rate and the log value added per capita (to control the labor market opportunities at the local level, which may in turn affect the children's career choices); the population growth rate (to capture trends and expectations regarding the change of the market power of pharmacies); the fraction of elderly people (who consume more pharmaceutical products); and south (a dummy to

\footnotetext{
${ }^{15}$ The estimated log difference in the height of the density is 0.20 , with a standard error of 0.27 around the first threshold (7,500 residents). The corresponding figures when pooling all thresholds are 0.15 and 0.21 , respectively.

${ }^{16}$ The public competition for new or vacant pharmacies is at the provincial level, and the assignment to specific cities is based on the final position in the pass list. In fact, according to the LFS, 97 percent of pharmacists did not change their residence to begin their current job. Thus, the spatial sorting of pharmacists and selective assignment to cities do not appear to be issues in our case.
} 
control for the traditional North-South divide in Italy). The differences in the local observables discussed thus far are not statistically significant, suggesting that the assignment to the treatment around the cut-off is randomized.

\subsection{Controlling for unobserved heterogeneity}

In the second empirical strategy, we consider the full sample of young people, abandoning the discontinuity framework and considering a different identification assumption. Namely, we assume that the pharmacists' children have a comparative advantage in the pharmacy market with respect to other young people because of the inheritability of the family business. This assumption is reasonable and is derived directly from the law. Indeed, the intergenerational transmission of a pharmacy's ownership is one of the most common ways to exercise the profession in retail trade. Therefore, ceteris paribus, the impact of the rent is expected to be relevant for pharmacists' children and less relevant (even negligible) for others. ${ }^{17}$ This allows us to run regressions of the following type:

$$
\text { pharmacist }_{i}^{c}=\rho \text { pharmacist }_{i}^{p}+\varphi \operatorname{rent}_{c(i)} \times \text { pharmacist }_{i}^{p}+\theta X_{i}+\lambda_{c(i)}+v_{i}
$$

where the dependent variable is the propensity of child $i$ to become a pharmacist; the key variables on the right-hand side are the parents' professions (i.e., a dummy equal to 1 if at least one parent is a pharmacist and 0 otherwise) and the interaction term between this dummy and $\operatorname{rent}_{c(i)}$; the interaction term captures the differential impact of the pharmacyto-population ratio between the pharmacists' children and other children. Importantly, the specification includes city-fixed effects $\left(\lambda_{c(i)}\right)$ that capture any unobserved variable that may be correlated to both the pharmacy-to-population ratio and dependent variable (and may thus bias our results). Finally, as a robustness check, we also include controls at the individual $(X)$ level. We expect a positive sign for $\rho$ - i.e., intergenerational persistence in the pharmacist profession - and a negative sign for $\varphi$ - i.e., an increase in the pharmacyto-population ratio would negatively affect the individual propensity to become a pharmacist, and this impact is stronger among pharmacists' children.

\section{Results}

In the first empirical strategy, we exploit discontinuities in the pharmacy-topopulation ratio due to regulations to identify the role of rents in career following. We restrict the analysis to pharmacists' children.

We begin with a graphical representation. Figure 9 plots the variation in the probability of being enrolled in a pharmacy degree program with population in our sample. The individual propensity to become a pharmacist gradually increases when approaching

\footnotetext{
${ }^{17}$ This is a testable assumption, and the placebo regressions discussed in Section 5 confirm this assumption.
} 
the first threshold, decreases sharply at this threshold, and again increases when moving away from the same threshold (and approaching the next one). The discontinuity is statistically significant. ${ }^{18}$ These patterns are consistent with our expectations. Indeed, economic rents progressively increase with increasing population and decrease sharply at the threshold values (when a new pharmacy is added). Examining the observations in the bandwidth $\pm 2,000$ around the threshold, living in a city just below the threshold increases the children's propensity to follow their parents' career path by nearly 12 percentage points (i.e., the probability of being enrolled in pharmacy program decreases sharply from 18 to 6 percent when moving from below to above the thresholds).

Unfortunately, a graphical inspection of each threshold is unreliable because the sample size is limited (i.e. the observations above and below the cut-offs are very sparse). Therefore, following Angrist and Lavy (1999), we adopt a more standard regression setting and consider the full sample of pharmacists' children. ${ }^{19}$ The baseline results are shown in Table 4: the top panel reports OLS estimates; the first column includes only the pharmacyto-population ratio and two variables capturing local economic opportunities (unemployment rate and log of valued added per capita); and the remaining columns include polynomial specifications of increasing order to the population. OLS estimates indicate a negative and statistically significant correlation between the pharmacy-topopulation ratio and children's propensity to follow in their parents' footsteps as pharmacists. The point estimates between the simplest specification and the specification with a fourth-degree polynomial in population are highly similar. The bottom panel reports instrumental variables estimates of the same specifications using the demographic criterion as an exogenous source of variation in the variable of interest. In the first stage, the regression is highly significant, with an R-squared of nearly 0.7 ; the bottom line of the table reports the F-statistics of the excluded instrument, which are well above the rule of thumb of 10 . The second-stage results are qualitatively similar to the OLS estimates, although the magnitudes are slightly increased. The effects are also substantial in magnitude. According to our preferred specification (last column), a one-standarddeviation increase in the pharmacy-to-population ratio would reduce the predicted probability of being enrolled in a pharmacy degree program by 0.9 of its standard deviation. Adopting a different perspective, adding a new pharmacy in each city would reduce children's probability of following in their parents' footsteps by approximately 4 percent (that is, approximately one fourth of the predicted probability).

We report additional robustness checks in Table 5. We add individual-level controls in column I and city-level controls in column II; both individual- and city-level controls are

\footnotetext{
${ }^{18}$ We consider the first threshold (approximately 7,500 residents) because it is the only threshold for which we have a sufficient number of observations above and below the cut-off. The observations for the other thresholds are sparse, thus undermining the reliability of a regression discontinuity analysis. Nevertheless, in unreported evidence (available from the author upon request), we replicate the analysis using observations in the bandwidth $\pm 2,000$ for all thresholds, and our results are qualitatively confirmed.

${ }^{19}$ For simplicity and to guarantee comparability across the different empirical exercises, the estimates are obtained through a linear probability model. However, in unreported evidence, we replicate Tables 4 to 6 (and Figure 9) with a probit model, and the results are unaffected (available upon request from the author).
} 
included in column III. Individual controls include children's age and gender, the number of children, and the age of the household's head. According to our findings, none of these variables - whose coefficients are not reported in the table for brevity - plays a significant role in explaining individual probability to enroll in pharmacy program. Local controls include the main social, economic, and demographic features of the city in which the individual resides. As expected, population growth and the fraction of elderly people (which capture the demand pressure on pharmaceutical products) are positively correlated with the propensity to become a pharmacist, whereas the other local controls are not correlated with our outcome variable. More importantly, our main findings are qualitatively similar, and the coefficient of the pharmacy-to-population ratio is fairly stable across the specifications. ${ }^{20}$

Table 6 presents the results of a placebo test based on the following argument. The existence of a large market power in a city, guaranteed by regulations, should make the profession of pharmacist more attractive. Therefore, one might expect a more pronounced tendency to enroll in a pharmacy degree program for young people living in that city. However, the law also establishes strong barriers to entry in the pharmacy market because one cannot be engaged in the trade without inheriting the business or acquiring (through a public competition) a new license when permitted by law (which would in turn reduce the market power at the local level). This scenario ensures a clear positional advantage for pharmacists' children and high barriers to entry for other children. Therefore, pharmacists' children are (reasonably) the only young people who are sensitive, in their career choice, to the local market power of pharmacies. To test this assumption, we replicate our analysis for non-pharmacists' children and for the children of doctors or somewhat-related professions. The latter subsample is considered to select a group of children with a family background similar to that of pharmacists. According to our findings, the pharmacy-topopulation ratio has a weakly positive impact on the propensity to become a pharmacist. This result appears to suggest a limited role for the demand of pharmacies, i.e., more pharmacies would represent more employment opportunities for potential pharmacists, which is clearly incompatible with the rent hypothesis. However, the statistical significance vanishes when we consider IV estimates. The OLS and IV coefficient estimates are not significant for the subsample of children of doctors or related professions. Overall, these results are consistent with our expectations: the local market power of pharmacies matters only for pharmacists' children due to their positional advantage for entry into that market.

Table 7 presents the results of a different empirical strategy that exploits the asymmetry between pharmacists' children and other children in terms of entry barriers in the profession. Specifically, we consider all the children in our sample and regress their propensity to become a pharmacist on a dummy for whether their parents are pharmacists themselves and on an interaction term obtained by multiplying this dummy with the pharmacy-to-population ratio; importantly, we also include city-fixed effects. The

\footnotetext{
${ }^{20}$ The F-statistics of the excluded instrument decrease from 30 to 19 when we include additional local controls. This specification appears to be too demanding relative to the identifying variation in the data.
} 
drawback of this specification is that we do not estimate the direct effect of economic rents but rather its differential impact depending on parents' professions. On the positive side, city-fixed effects allow us to control any unobserved local factors that may be related to both the pharmacy-to-population ratio and the dependent variable. Column I is the baseline specification, whereas column II is enriched with other individual and household variables. Based on these findings, being a child of a pharmacist increases an individual's propensity to become a pharmacist by 18 percentage points. Moreover, the interaction term has a negative sign, as expected, and is statistically significant, suggesting that economic rents disproportionately affect the propensity to become a pharmacist for those who are the children of a pharmacist. The estimated impact is even stronger, as we have observed above, if we replicate these specifications in cities with less than 20,000 residents (columns III and IV).

\section{Conclusion}

The existence of dynasties in professions is well known, as documented in both empirical studies and a number of anecdotal stories. Unfortunately, a portion of the underlying mechanism remains unexplained. However, understanding the underlying causes of the intergenerational persistence in income, social class, and/or professions is important in designing proper policies to attenuate the role of those factors that are considered unfair.

To the best of our knowledge, this paper is the first to provide evidence of the causal impact of rents on intergenerational linkages. To this end, we focus on the profession of pharmacists, which exhibits a positional advantage based on the inheritability of the family business and discontinuities (established by law) in the relationship between the number of pharmacies and the population. These features have been exploited in several identification strategies, the results of which can be summarized as follows. Adding a new pharmacy in each city would reduce the probability of pharmacists' children enrolling in a pharmacy degree program by 4 percentage points, that is, approximately one fourth of the predicted probability. The impact of economic rents is highly significant for the career choices of pharmacists' children and negligible for other children, suggesting that the inheritance of the family business significantly affects the intergenerational persistence among pharmacists. Although a precise accounting of each channel is not technically possible, we reasonably suggest that positional rents (the inheritability of the business and the economic rents guaranteed by favorable pharmacy-to-population ratios) explain the majority of the gap in the propensity to become a pharmacist between pharmacists' children (15.9 percent) and all other children (1.3 percent). The policy implications of these results are clear: the removal of guild privileges and anti-competitive regulations may significantly increase social fluidity. ${ }^{21}$

\footnotetext{
${ }^{21}$ Moreover, this may also lead to other desirable outcomes, such as an increase in the overall economic efficiency. Indeed, Bandiera et al. (2009) find that when managers favor the workers to whom they are
} 
The extent to which economic rents contribute to cross-country and cross-profession variations in social fluidity remains unclear. Cross-country variation is typically explained in terms of different institutions, with a special emphasis on education policies (e.g., early childhood care, early tracking in secondary education, and financial support in tertiary education), which may offset environmental advantages and ensure equal access to education and the labor market (OECD, 2010). However, a portion of the variance remains unexplained, suggesting that other factors, such as labor market regulation and positional rents, may play a role, as shown in Figure 4. Cross-profession variation is typically associated with job-specific abilities and preferences (which may be correlated with upbringing) and social networks. However, professions differ markedly in terms of entry regulation, and our findings indicate that these factors may have significant effects. Unsurprisingly, some of the occupations and professions that record a higher persistence (as shown in Figures 2 and 3) belong to less market-oriented sectors. Overall, we believe that the roles of regulation and rents are sufficiently significant to warrant further attention.

socially connected this has a detrimental effect on the firm's overall performance. Somewhat similarly, a study by Perez-Gonzales (2006) shows that firms that promote related CEOs - by either blood or marriage significantly underperform relative to firms that promote unrelated CEOs. 


\section{References}

Angrist, J.D. and V. Lavy (1999), Using Maimonides' rule to estimate the effect of class size on scholastic achievement, Quarterly Journal of Economics,114: 533-575.

Bandiera, O., I. Barankay and I. Rasul (2009), Social connections and incentives in the workplace: evidence from personnel data, Econometrica, 77: 1047-1094.

Basso, G. and G. Labartino (2011), Family connections in accessing licensed occupations in Italy, in M. Pellizzari et al. (ed.), Family ties in licensed profession in Italy, Fondazione Rodolfo de Benedetti.

Björklund, A. and M. Jäntti (2009), Intergenerational income mobility and the role of family background, in W. Salverda, B. Nolan and T. Smeeding (eds.), Handbook of Economic Inequality, Oxford University Press.

Björklund, A., M. Lindahl and E. Plug (2006), The origins of intergenerational associations: lessons from Swedish adoption data, Quarterly Journal of Economics, 121: 999-1028.

Björklund, A., J. Roine and D. Waldenström (2012), Intergenerational top income mobility in Sweden: capitalist dynasties in the land of equal opportunity? Journal of Public Economics, 96: 474-484.

Black, S.E. and P.J. Devereux (2011), Recent developments in intergenerational mobility, in O. Ashenfelter and D. Card (eds.), Handbook in Labor Economics, North Holland.

Bowles, S., H. Gintis and M. Osborne Groves (2005), Unequal chances: family background and economic success, Princeton University Press.

Calzolari, G., A. Ichino, F. Manaresi and V. Nellas (2013), When the baby cries at night: inelastic buyers in non-competitive markets, Bank of Italy working papers 914.

Catania, A. and P. Monti (2011), Institutional aspects of licensed occupations in Italy, in M. Pellizzari et al. (ed.), Family ties in licensed profession in Italy, Fondazione Rodolfo de Benedetti.

Corak, M. (2013), Income inequality, equality of opportunity, and intergenerational mobility, Journal of Economic Perspective, 27: 79-102.

Corak, M. and P. Piraino (2011), The intergenerational transmission of employers, Journal of Labor Economics, 29: 37-68.

Dunn, T. and D. Holtz-Eakin (2000), Financial capital, human capital, and the transition to self-employment: evidence from intergenerational links, Journal of Labor Economics, 18: 282-305.

Durante, R., G. Labartino and R. Perotti (2011), Academic dynasties: decentralization and familism in the Italian academia, NBER working paper 17572.

Granovetter, M. (2005), The impact of social structure on economic outcomes, Journal of Economic Perspectives, 19: 33-50.

Ichino, A., L. Karabarbounis and E. Moretti (2011), The political economy of intergenerational income mobility, Economic Inquiry, 49: 47-69. 
Ioannides, Y.M and L.D. Loury (2004), Job information networks, neighborhood effects, and inequality, Journal of Economic Literature, 42: 1056-1093.

Jencks, C. and L. Tach (2006), Would equal opportunity mean more mobility?, in S.B. Morgan, D.L. Grusky and G.S. Fields (eds.), Mobility and inequality: frontiers of research from sociology and economics, Stanford University Press.

Kleiner, M.M. and A.B. Krueger (2013), Analyzing the extent and influence of occupational licensing on the labor market, Journal of Labor Economics, 31: 173-202.

Laband, D.N. and B.F. Lentz (1992), Self-recruitment in the legal profession, Journal of Labor Economics, 10: 182-201.

Lee, D.S. and T. Lemieux (2010), Regression discontinuity designs in economics, Journal of Economic Literature, 48: 281-355.

Lentz, B.F. and D.N. Laband (1989), Why so many children of doctors become doctors, Journal of Human Resources, 24: 396-413.

McCrary, J. (2008), Manipulation of the running variable in the regression discontinuity design: a density test, Journal of Econometrics, 142: 698-714.

Mocetti, S. (2007), Intergenerational earnings mobility in Italy, B.E. Journal of Economic Analysis and Policy, 7, (2).

OECD (2010), A family affair: intergenerational social mobility across OECD countries, in Going for growth, OECD Publishing.

OECD (2011), Product Market Regulation Database.

Perez-Gonzales, F. (2006), Inherited control and firm performance, American Economic Review, 96: 1559-1588.

Roemer, J.E. (2002), Equality of opportunity: a progress report, Social Choice and Welfare, 19: 455-471.

Roemer, J.E. (2004), Equal opportunity and intergenerational mobility: Going beyond intergenerational income transition matrices, in M. Corak (ed.), Generational income mobility in North America and Europe, Cambridge University Press.

Sacerdote, B. (2011), Nature and nurture effects on children's outcomes: what have we learned from studies of twins and adoptees? in J. Benhabib, M.O. Jackson and A. Bisin (eds.), Handbook of Social Economics, North Holland.

Smeeding, T.M., R. Erikson and M. Jäntti (2011), Introduction, in T.M. Smeeding, R. Erikson and M. Jäntti (eds.), Persistence, privilege, and parenting, Russell Sage Foundation.

Solon, G. (2002), Cross-country differences in intergenerational earnings mobility, Journal of Economic Perspectives, 16: 59-66. 20: 1-11.

Swift, A. (2004), Would perfect mobility be perfect? European Sociological Review, 


\section{Figure}

Figure 1. Intergenerational income elasticity: cross-country comparison

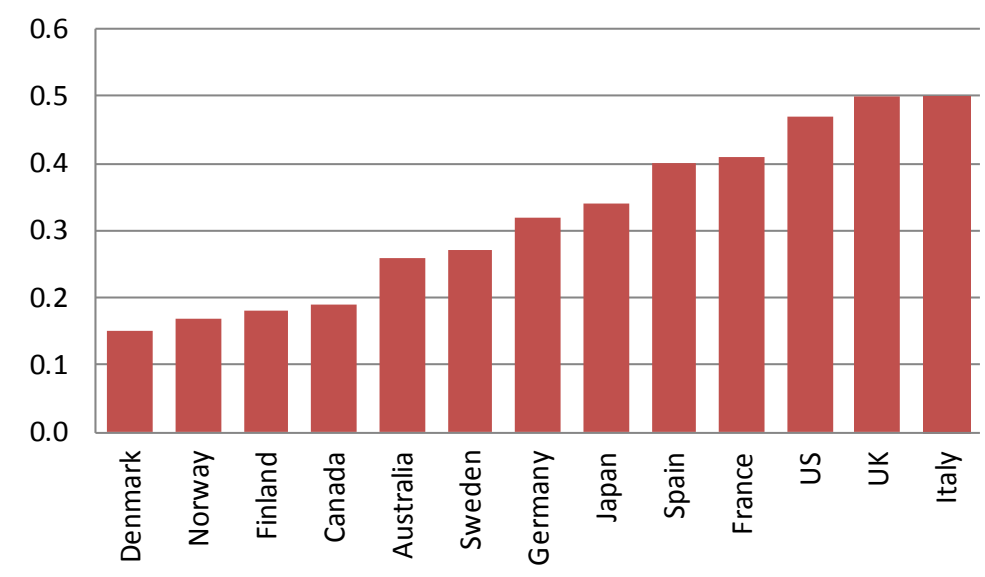

The figures refer to the country estimates of intergenerational income elasticity, a summary indicator that measures the degree to which economic differences among individuals persist across generations. The magnitude of the coefficient, among the countries studied so far, varies between 0 and 1 . A value close to 1 indicates the individual's position in the income distribution is largely a reflection of his parents' position in their distribution. A value close to 0 indicates a very mobile society in which an individual's income does not strongly depend on his parental background. Figures are drawn from Corak (2013).

Figure 2. Intergenerational persistence: cross-occupation comparison

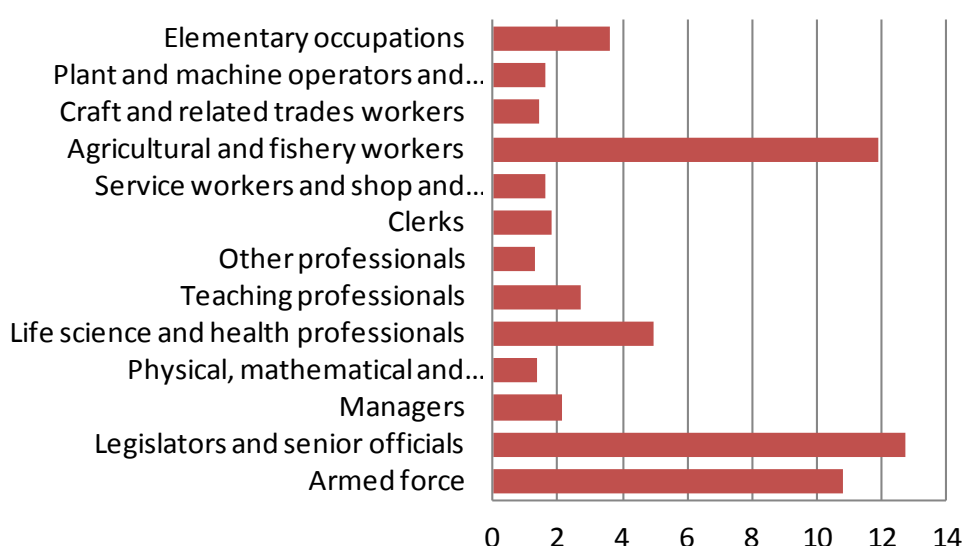

The figures refer to the probability of being employed in a certain occupation among children of parents employed in the same occupation relatively to the corresponding probability for overall population. Values larger than 1 indicate disproportional career following. Author's elaboration on data from EU-SILC 2005 
Figure 3. Family connections among member of professions in Italy

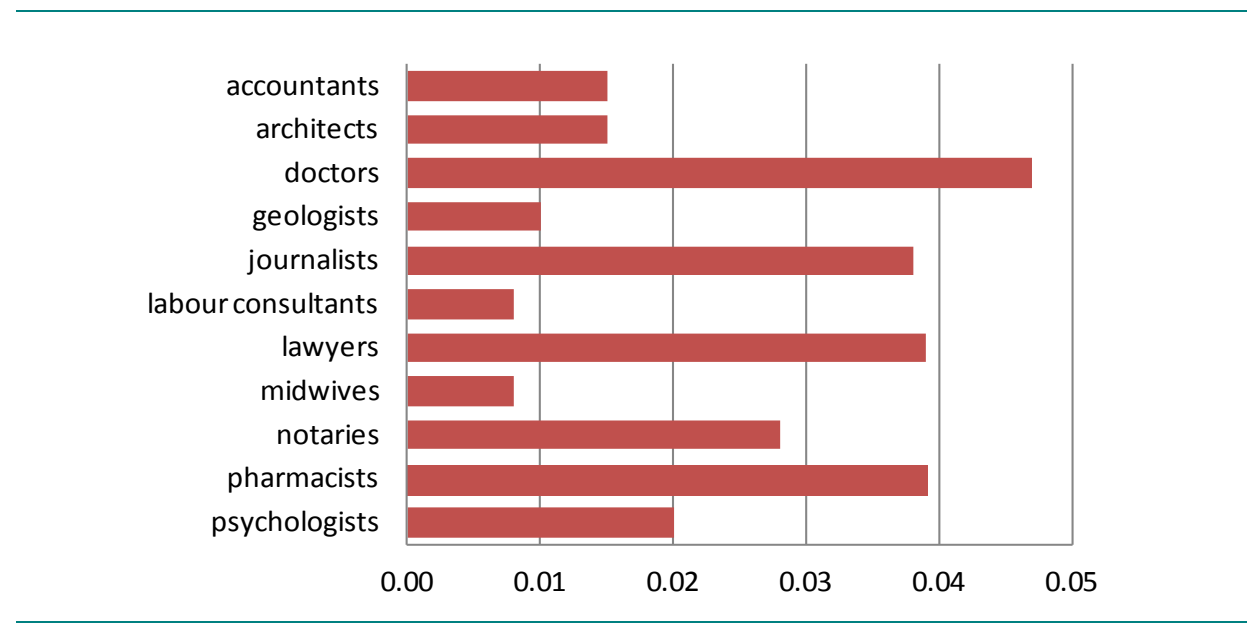

Figures represent the pseudo-ICS, a measure which exploits the informative content of surnames to capture the strength of family connections in liberal professions. Figures are drawn from Basso and Labartino (2011)

Figure 4. Intergenerational mobility and regulation in professional services

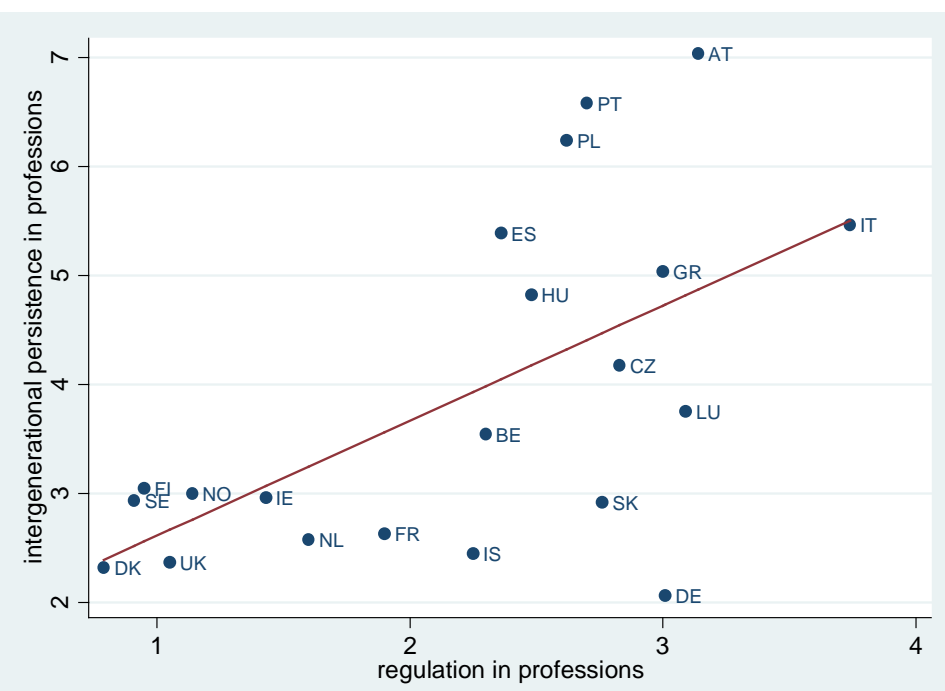

Intergenerational persistence in professions measures the probability to become a member of professions if one's parent is a member of profession relatively to the corresponding probability for overall population; author's elaborations on data drawn from EU-SILC (2005); we consider categories 21 and 24 of the ISCO-88 2-digit level classification and which include, among others, computing professionals, architects, engineers and business and legal professionals. Regulation in professions in drawn from OECD (2011) and refers to the strictness of regulation in the following professional services: accounting, architects, engineers and legal professions. 
Figure 5. Incomes among member of professions in Italy

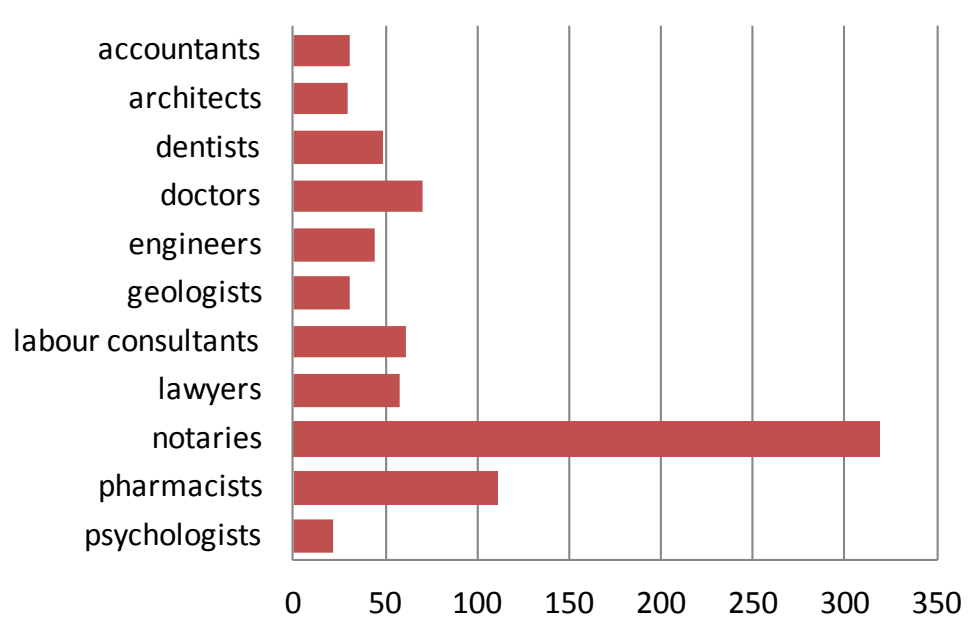

Figures represent the incomes of member of professions as evaluated by the Sector Studies (Studi di settore) carried out by the Revenue Agency.

Figure 6. Enrolment in pharmacy

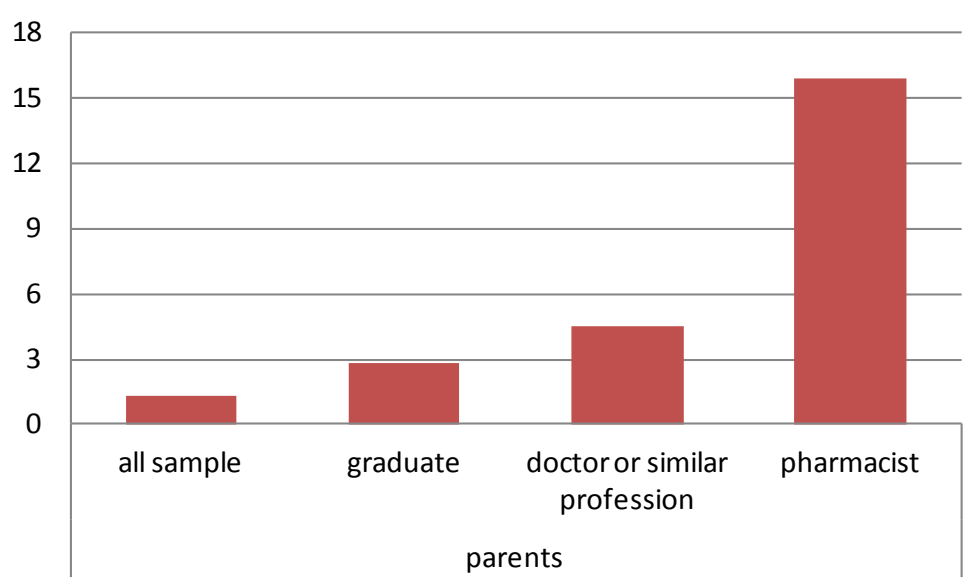

Figures refer to the probability of being enrolled in a pharmacy degree program by parental background. Specifically, "graduate" refers to households where at least one parent has a university degree; "doctor or similar profession" refers to households where at least one parent is a doctor or a specialist in mathematical, physical, chemical or natural sciences; "pharmacist" refers to household where at least one parent is a pharmacist. Author's elaboration on data from LFS. 
Figure 7. Number of pharmacies and city size

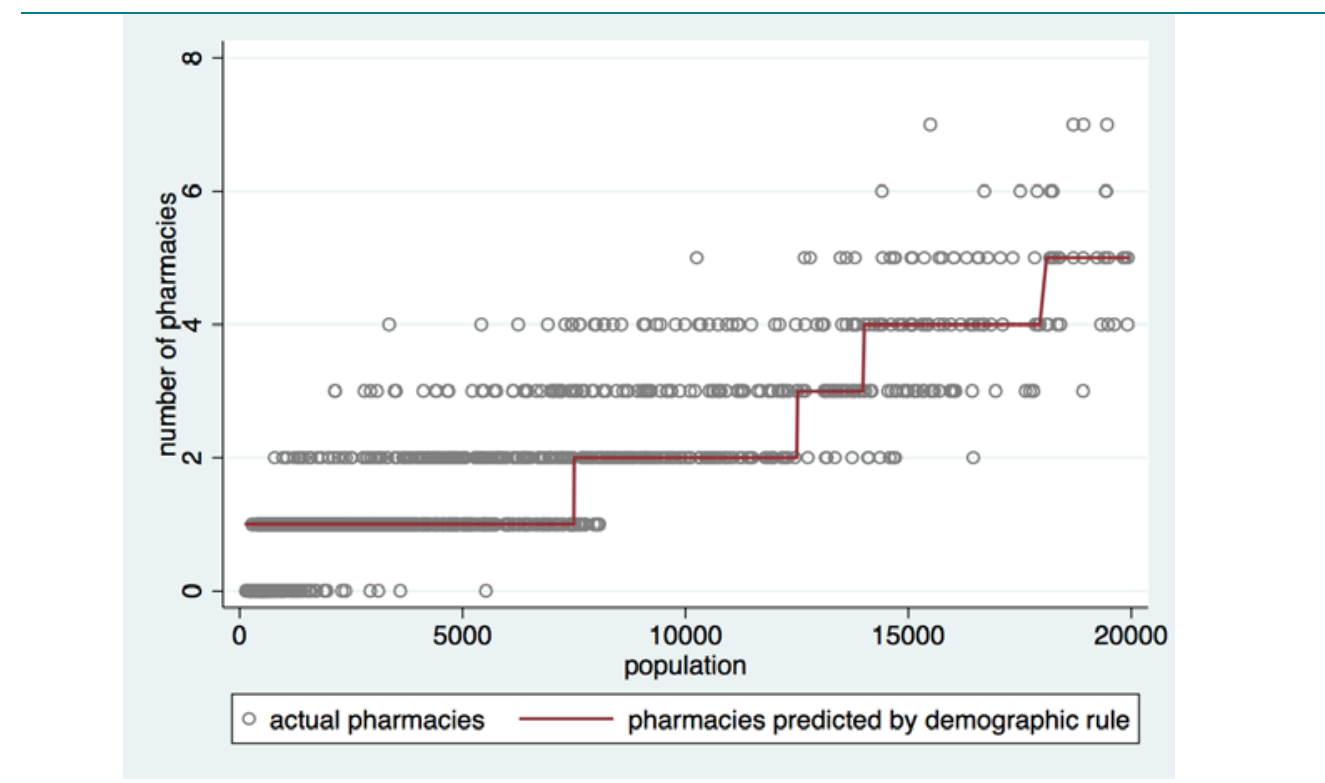

Dots represent, for each city, the number of pharmacies; the line represents the number of pharmacies predicted by the demographic criterion; figures refer to cities with less than 20,000 residents. Author's elaboration on data from the Ministry of Health and Istat.

Figure 8. Distribution of cities across thresholds

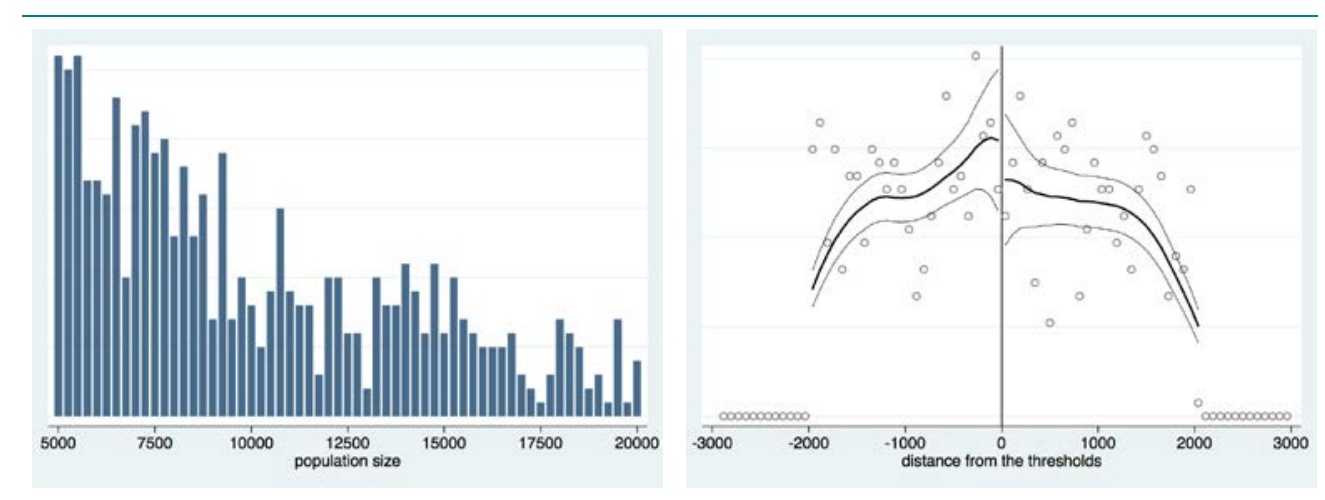

Histograms on the left panel plot population density for cities with less than 20,000 residents; plot on the right panel represents distribution of cities below and above the thresholds, pooling observations from all cities, obtained using the routine provided by McCrary (2008). Author's elaboration on data from the Ministry of Health and Istat. 
Figure 9. Propensity to become a pharmacist

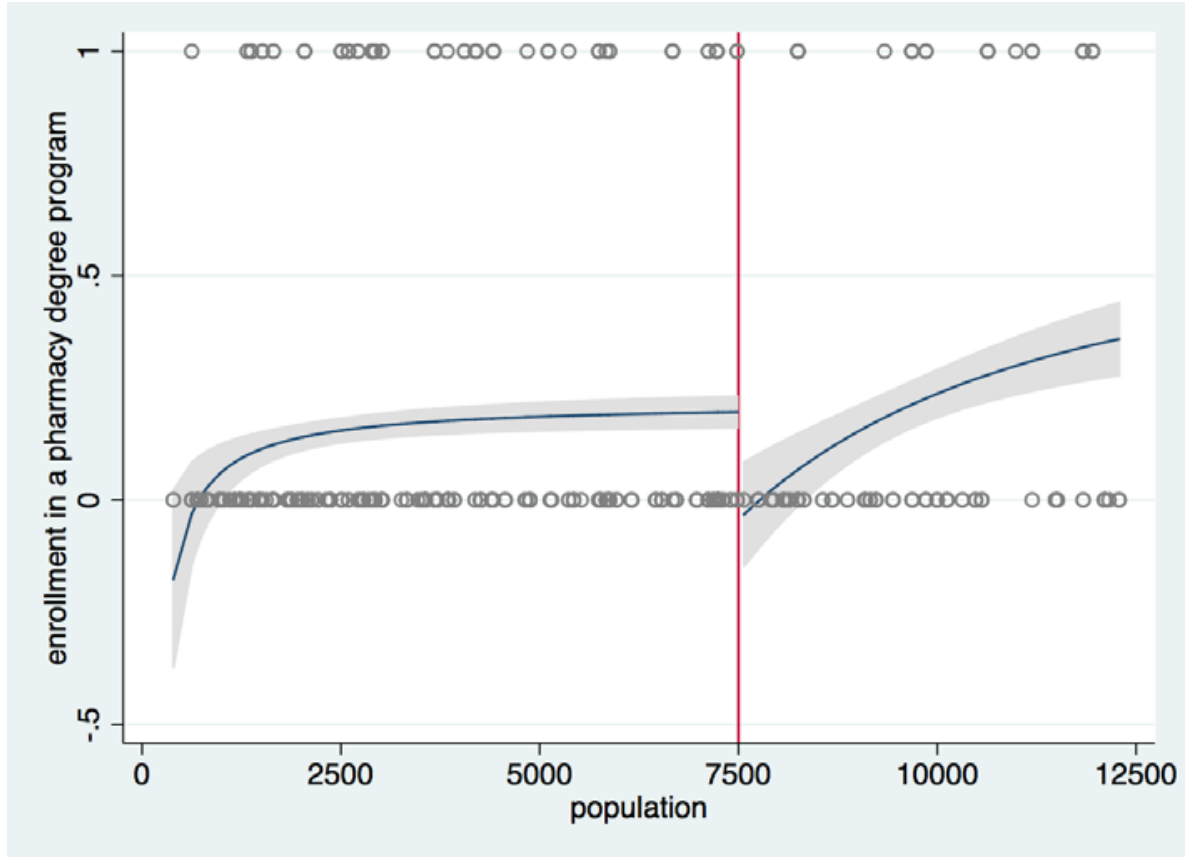

Scatter plot and local polynomial smoothing regressions of the enrollment in a pharmacy degree program with respect to population; 7,500 residents is the first threshold defined by the demographic criterion. Author's elaboration on data from LFS, Ministry of Health and Istat. 


\section{Tables}

Table 1. Descriptive statistics of the sample

\begin{tabular}{lcc} 
& Children & Household's head \\
\hline Age & $21.40(2.274)$ & $52.34(6.161)$ \\
Female & $0.473(0.499)$ & $0.153(0.360)$ \\
University & $0.325(0.468)$ & $0.094(0.292)$ \\
Pharmacist & $0.013(0.112)$ & \\
\# observations & & $0.004(0.064)$ \\
\hline
\end{tabular}

Figures refer to mean values (standard deviation in parenthesis); "university" refers to the fraction of children enrolled at university and to the fraction of parents with a university degree, respectively; "pharmacist" refers to the fraction of children attending a pharmacy degree program and to the fraction of parents who are pharmacist, respectively

Table 2. Observed and predicted pharmacy-to-population ratio

\begin{tabular}{lccccc} 
& Degree 0 & Degree 1 & Degree 2 & Degree 3 & Degree 4 \\
\hline Predicted pharmacy-to-population ratio & $0.189 * * *$ & $0.185^{* * *}$ & $0.177^{* * *}$ & $0.163^{* * *}$ & $0.153^{* * *}$ \\
& $(0.035)$ & $(0.035)$ & $(0.035)$ & $(0.035)$ & $(0.035)$ \\
Observations & 2,244 & 2,244 & 2,244 & 2,244 & 2,244 \\
R-squared & 0.085 & 0.088 & 0.096 & 0.108 & 0.118 \\
\hline
\end{tabular}

The dependent variable is observed pharmacy-to-population ratio; the key explanatory variable is the pharmacy-to-population ratio predicted by the demographic criterion. The polynomial in the forcing variable (population) is of zero, first, second, third and fourth degree, respectively (corresponding parameters are not reported). Regressions are at the city level and robust standard errors are reported in parenthesis; * significant at $10 \%$; ${ }^{*}$ significant at $5 \%$; and ${ }^{* * *}$ significant at $1 \%$.

Table 3. Differences in means above and below the threshold

\begin{tabular}{llll} 
Variable & \multicolumn{1}{c}{ I } & II & III \\
\hline Number of pharmacies & $0.983(0.432)^{* *}$ & $0.627(0.111)^{* * *}$ & $0.404(0.149)^{* * *}$ \\
Unemployment rate & $0.050(0.699)$ & $-0.172(0.886)$ & $-0.693(1.186)$ \\
Log of value added per capita & $0.021(0.027)$ & $0.043(0.036)$ & $0.041(0.048)$ \\
Fraction of elderly people & $0.002(0.003)$ & $0.000(0.003)$ & $0.002(0.005)$ \\
Population growth rate & $0.002(0.007)$ & $0.013(0.011)$ & $0.006(0.014)$ \\
South & $-0.045(0.034)$ & $-0.049(0.043)$ & $-0.066(0.059)$ \\
\hline
\end{tabular}

Pooling of observations from all thresholds; we consider observations in the bandwidth $\pm 2,000$ residents in columns I and II and in the bandwidth $\pm 1,000$ in column III; columns II and III refer to cities with less than 20,000 residents; figures refer to statistical differences in means: * significant at $10 \%$; ** significant at $5 \%$; and *** significant at $1 \%$. 
Table 4. The effect of pharmacies' rents: baseline

OLS estimates

\begin{tabular}{lccccc}
\hline & Degree 0 & Degree 1 & Degree 2 & Degree 3 & Degree 4 \\
\cline { 2 - 6 } Pharmacy-to-population & $-0.140^{* *}$ & $-0.142^{* *}$ & $-0.143^{* *}$ & $-0.145^{* *}$ & $-0.163^{* *}$ \\
& $(0.068)$ & $(0.068)$ & $(0.068)$ & $(0.069)$ & $(0.069)$ \\
Observations & 1,526 & 1,526 & 1,526 & 1,526 & 1,526 \\
& & & IV estimates \\
& & & & \\
\hline Pharmacy-to-population & $-0.234 * * *$ & $-0.233^{* * *}$ & $-0.230 * * *$ & $-0.233^{* * *}$ & $-0.256^{* * *}$ \\
Observations & $(0.073)$ & $(0.073)$ & $(0.073)$ & $(0.075)$ & $(0.077)$ \\
First stage F-statistics & 1,526 & 1,526 & 1,526 & 1,526 & 1,526 \\
\hline
\end{tabular}

The sample includes pharmacists' children; the dependent variable is children propensity to become a pharmacist (i.e. being enrolled in a pharmacy degree program); the key explanatory variable is the pharmacy-to-population ratio. The polynomial in the forcing variable (population) is of zero, first, second, third and fourth degree, respectively; each specification also includes the unemployment rate and the log of value added per capita (parameters of the control variables are not reported). Top panel refers to OLS estimation while bottom panel refers to IV estimates (using the pharmacy-to-population ratio predicted by the demographic criterion as instrumental variable). Standard errors are clustered at the city level; * significant at $10 \%$; ** significant at $5 \%$; and *** significant at $1 \%$

Table 5. The effect of pharmacies' rents: robustness

\begin{tabular}{|c|c|c|c|}
\hline & \multicolumn{3}{|c|}{ OLS estimates } \\
\hline & $\mathbf{I}$ & II & III \\
\hline \multirow[t]{2}{*}{ Pharmacy-to-population ratio } & $-0.153^{* *}$ & $-0.137^{*}$ & $-0.131 * *$ \\
\hline & $(0.066)$ & $(0.082)$ & $(0.077)$ \\
\hline Individual controls & $\sqrt{ }$ & & $\sqrt{ }$ \\
\hline Local controls & & $\sqrt{ }$ & $\sqrt{ }$ \\
\hline \multirow[t]{3}{*}{ Observations } & 1,526 & 1,526 & 1,526 \\
\hline & \multicolumn{3}{|c|}{ IV estimates } \\
\hline & $\mathbf{I}$ & II & III \\
\hline \multirow[t]{2}{*}{ Pharmacy-to-population ratio } & $-0.249 * * *$ & $-0.274^{* *}$ & $-0.270 * *$ \\
\hline & $(0.076)$ & (0.108) & $(0.106)$ \\
\hline Individual controls & $\sqrt{ }$ & & $\sqrt{ }$ \\
\hline Local controls & & $\sqrt{ }$ & $\sqrt{ }$ \\
\hline Observations & 1,526 & 1,526 & 1,526 \\
\hline First stage F-statistics & 29.6 & 19.3 & 19.2 \\
\hline \multicolumn{4}{|c|}{$\begin{array}{l}\text { The sample includes pharmacists' children; the dependent variable is children propensity to become a pharmacist } \\
\text { (i.e. being enrolled in a pharmacy degree program); the key explanatory variable is the pharmacy-to-population ratio. } \\
\text { Each specification includes a fourth degree polynomial in the forcing variable (population), unemployment rate and } \\
\text { log of value added per capita. Individual controls include gender, age and number of children; local controls include } \\
\text { population growth rate, fraction of elderly people and dummies for geographical areas. Top panel refers to OLS } \\
\text { estimation while bottom panel refers to IV estimates (using the pharmacy-to-population ratio predicted by the } \\
\text { demographic criterion as instrumental variable). Standard errors are clustered at the city level; * significant at } 10 \% \text {; }{ }^{* *} \\
\text { significant at } 5 \% \text {; and }{ }^{* \star *} \text { significant at } 1 \% \text {. }\end{array}$} \\
\hline
\end{tabular}


Table 6. The effect of pharmacies' rents: placebo

All children

\begin{tabular}{|c|c|c|c|c|}
\hline Pharmacy-to-population ratio & $\begin{array}{c}0.008 * * * \\
(0.003)\end{array}$ & $\begin{array}{c}0.004 \\
(0.003)\end{array}$ & $\begin{array}{c}0.001 \\
(0.003)\end{array}$ & $\begin{array}{l}-0.005 \\
(0.004)\end{array}$ \\
\hline Controls & baseline & all & baseline & all \\
\hline Estimation strategy & OLS & OLS & IV & IV \\
\hline Observations & 330,160 & 330,160 & 330,160 & 330,160 \\
\hline \multirow[t]{2}{*}{ First stage F-statistics } & & & 235.2 & 170.4 \\
\hline & \multicolumn{4}{|c|}{ Children of doctors or other related professions } \\
\hline \multirow[t]{2}{*}{ Pharmacy-to-population ratio } & 0.084 & 0.092 & 0.083 & 0.079 \\
\hline & $(0.060)$ & $(0.060)$ & $(0.068)$ & $(0.077)$ \\
\hline Controls & baseline & all & baseline & all \\
\hline Estimation strategy & OLS & OLS & IV & IV \\
\hline Observations & 6,987 & 6,987 & 6,987 & 6,987 \\
\hline First stage F-statistics & & & 69.6 & 57.3 \\
\hline \multicolumn{5}{|c|}{$\begin{array}{l}\text { The sample includes all children of non-pharmacists in the top panel and all children of doctors and related professions in } \\
\text { the bottom panel; the dependent variable is children propensity to become a pharmacist (i.e. being enrolled in a pharmacy } \\
\text { degree program); the key explanatory variable is the pharmacy-to-population ratio. Baseline controls include a fourth } \\
\text { degree polynomial in the forcing variable (population), unemployment rate and log of value added per capita; all controls } \\
\text { include other individual (gender, age and number of children) and local (population growth rate, fraction of elderly people } \\
\text { and dummies for geographical areas) controls. The first two columns, in each panel, refer to OLS estimation while the latte } \\
\text { two columns refer to IV estimates (using the pharmacy-to-population ratio predicted by the demographic criterion as as } \\
\text { instrumental variable). Standard errors are clustered at the city level; * significant at } 10 \% \text {; ** significant at 5\%; and ** } \\
\text { significant at } 1 \% \text {. }\end{array}$} \\
\hline
\end{tabular}

Table 7. The effect of pharmacies' rents: controlling for unobserved heterogeneity

OLS estimates with city-fixed effects

\begin{tabular}{lcccc}
\hline & I & II & III & IV \\
\cline { 2 - 5 } Parent is pharmacist & $0.180^{* * *}$ & $0.179 * * *$ & $0.212^{* * *}$ & $0.211^{* * *}$ \\
& $(0.024)$ & $(0.024)$ & $(0.038)$ & $(0.038)$ \\
Interaction term & $-0.082^{*}$ & $-0.081^{*}$ & $-0.120^{* *}$ & $-0.119 * *$ \\
& $(0.043)$ & $(0.043)$ & $(0.049)$ & $(0.049)$ \\
City-fixed effects & $\sqrt{ }$ & $\sqrt{ }$ & $\sqrt{ }$ & $\sqrt{ }$ \\
Individual controls & all & $\sqrt{ }$ & & $\sqrt{ }$ \\
Sample & 331,713 & 331,713 & 179,981 & 179,981 \\
Observations & & all &
\end{tabular}

The sample includes all youngsters; the dependent variable is children propensity to become a pharmacist (i.e. being enrolled in a pharmacy degree program); the key explanatory variable is the interaction term between pharmacy-topopulation ratio and parents' profession (i.e. a dummy equal to 1 if at least one parent is a pharmacist). Each specification includes city fixed effects which captures all unobserved city heterogeneity. Individual controls include gender, age, parents' age and number of children; in columns III and IV the sample is restricted to cities with less than 20,000 residents. Standard errors are clustered at the city level; * significant at 10\%; ** significant at 5\%; and *** significant at $1 \%$. 